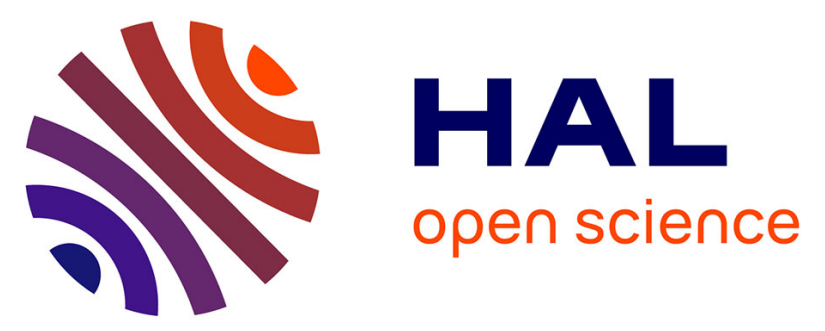

\title{
Comparison between absorbed dose to water standards established by water calorimetry at the LNE-LNHB and by application of international air-kerma based protocols for kilovoltage medium energy x-rays
}

Nicolas Perichon, Benjamin Rapp, Marc Denozière, Josiane Daures, Aimé Ostrowsky, Jean-Marc Bordy

\section{To cite this version:}

Nicolas Perichon, Benjamin Rapp, Marc Denozière, Josiane Daures, Aimé Ostrowsky, et al.. Comparison between absorbed dose to water standards established by water calorimetry at the LNE-LNHB and by application of international air-kerma based protocols for kilovoltage medium energy x-rays. Physics in Medicine and Biology, 2013, 58 (9), pp.2787 - 2806. 10.1088/0031-9155/58/9/2787 . cea01816330

\author{
HAL Id: cea-01816330 \\ https://hal-cea.archives-ouvertes.fr/cea-01816330
}

Submitted on 25 Feb 2022

HAL is a multi-disciplinary open access archive for the deposit and dissemination of scientific research documents, whether they are published or not. The documents may come from teaching and research institutions in France or abroad, or from public or private research centers.
L'archive ouverte pluridisciplinaire HAL, est destinée au dépôt et à la diffusion de documents scientifiques de niveau recherche, publiés ou non, émanant des établissements d'enseignement et de recherche français ou étrangers, des laboratoires publics ou privés. 


\title{
Comparison between absorbed dose to water references established by water calorimetry at LNE-LNHB and by application of international protocols based on references in terms of air kerma for kilovoltage medium energy $\mathrm{X}$-rays.
}

\author{
N. PERICHON, B.RAPP, M.DENOZIERE, J.DAURES, A.OSTROWSKY, J-M.BORDY \\ Laboratoire National Henri Becquerel, \\ Institut CEA LIST \\ CEA Saclay
}

\begin{abstract}
Until now, the only way to determine absorbed dose to water for medium energy X-ray beams was to calculate it from references in terms of air kerma by application of international dosimetric protocols. New standards in terms of absorbed dose to water had just been established at LNELNHB, the French primary standard laboratory for ionizing radiation, thanks to water calorimetry, for medium energy $X$-rays in the reference conditions described by protocols (at $2 \mathrm{~cm}$ depth in water). The aim of this study is to compare these new references in terms of absorbed dose to water measured by calorimetry in six medium energy X-ray beams to the dose values calculated from the application of four international protocols based on references in terms of air kerma: IAEA TRS277, AAPM TG-61, IPEMB, NCS-10. The acceleration potentials of these beams are $80 \mathrm{kV}$; $120 \mathrm{kV} ; 150 \mathrm{kV} ; 180 \mathrm{kV} ; 250 \mathrm{kV}$ and $300 \mathrm{kV}$ with half value layers between $3.01 \mathrm{~mm}$ of aluminum and $3.40 \mathrm{~mm}$ of copper. A difference lower than $2.1 \%$ was reported between the two methods. Standard uncertainty of water calorimetry being below $0.8 \%$, the one associated to the values from protocols being around $2.5 \%$, results are consistent considering the uncertainties. Calibration factors in terms of absorbed dose to water, established by application of calorimetry and air kerma dosimetric protocols were also compared. It appears that calibration factors established thanks to AAPM TG-61 protocol are in best agreement with the calibration factor established by water calorimetry.
\end{abstract}

\section{Introduction}

Medium energy X-rays, which tube high voltage is between $80 \mathrm{kV}$ and $300 \mathrm{kV}$, are used in radiotherapy for low depth dose delivery (from millimeters to a few centimeters). These beams are used in some skin cancer treatments for lentigo maligna, kaposi's sarcoma for example [1-5]. They are also used for palliative care in the case of treatment of superficial rib metastases [5-7]. The other field of application of kilovoltage medium energy X-rays is imaging. Even if dose delivered by imaging are significantly lower than the ones delivered by radiotherapy, a current issue is how to take into account the dose received in the whole treatment process including $\mathrm{kVCT}$ imaging performed in order to plan the treatments or for the positioning of the patients.

The quantity of interest in radiotherapy is the absorbed dose to water. Currently, the only references available for medium energy X-ray beams are based on air kerma. The transfer dosimetric techniques described in international radiotherapy protocols and using air kerma have to be used in order to determine the absorbed dose to water. The reference conditions for these beams are described in protocols (IAEA TRS398 [8] for example) which recommend: a $2 \mathrm{~cm}$ reference depth in water, a $10 \times 10 \mathrm{~cm}^{2}$ irradiation field size at the reference depth and a distance source point of reference equals to the "usual treatment distance". Moreover, in accordance with international protocols [8-12], the limit between medium and high energy X-ray beams is arbitrarily defined by a tube high voltage of $300 \mathrm{kV}$. The limit between low and medium energy X-ray beams is not well 
defined and varies with protocols.

In order to be able to apply dosimetric protocols using references in terms of absorbed dose to water, LNE-LNHB the French primary standard laboratory for ionizing radiation, had just set up new references in terms of absorbed dose to water for six medium energy X-ray beams in reference conditions of the protocols, using water calorimetry technique.

Calorimetric measurements were performed in six medium energy $\mathrm{X}$ ray beams: IEC61267 RQR6; IEC 61267 RQR9; IEC 61267 RQR10; CCRI 180; CCRI 250; ISO4037 selected among the norms and protocols ISO 4037 [13] ; IEC 61267 [14] and CCRI [15] (see Table 1).

Basic principle of water calorimetry is to determine absorbed dose to water by measurements of temperature rise under irradiation knowing the specific heat capacity of water [16-20]. Measurements are performed with a water calorimeter running at $4{ }^{\circ} \mathrm{C}$.

Experimentally, some correction factors have to be considered and the absorbed dose to water is given by equation 1 :

$$
D_{w}=C_{p} \Delta T(1-h)^{-1} k_{c} k_{p} k_{\rho} k_{p r o f}
$$

with,

$C_{p} \quad$ the specific heat capacity of water for constant pressure at $4^{\circ} \mathrm{C}$. Its value internationally adopted is $4204.8 \mathrm{~J} \cdot \mathrm{kg}^{-1} \cdot \mathrm{K}^{-1}$ [21].

$\Delta T$ the temperature rise measured under irradiation. It is measured thanks to temperature probes inside a quartz vessel filled with ultrapure water.

$h$ the water heat defect which takes into account the water radiolysis reactions under irradiation which can disturb the temperature rise measurements [22].

$k_{\mathrm{c}} \quad$ the thermal conduction effect correction factor. This factor takes into account the disturbance of temperature rise induced by the different thermal conductivity of material surrounding the point of measurement (quartz of the vessel containing the water in which measurements are performed).

$k_{\mathrm{p}} \quad$ the dosimetric perturbation correction factor. This factor takes into account the dosimetric perturbation induced by the calorimeter itself on measurements.

$k_{\rho} \quad$ calorimetric measurements being realized at $4^{\circ} \mathrm{C}$ and references being established at $20^{\circ} \mathrm{C}$, this factor takes into account the difference of attenuation due to the difference of water density at these two temperatures.

$k_{\text {prof }} \quad$ the thermistor probes depth correction factor.

A new water calorimeter was set up at LNE-LNHB in order to perform measurements at a $2 \mathrm{~cm}$ depth in water, which is the reference depth recommended by protocols for medium energy X-ray beams. A $10 \times 10 \mathrm{~cm}^{2}$ irradiation field was used at the reference depth at $50 \mathrm{~cm}$ from the source. A schematic drawing of the LNE-LNHB water calorimeter is given Figure 1.

This calorimeter is the first one among the primary standard laboratories to be able to realize measurements at $2 \mathrm{~cm}$ depth. Measurements at such a low depth were made possible by embedding the vessel, in which temperature rise measurements are performed, into the water phantom. 
Results in terms of absorbed dose rate to water and their associated uncertainties are presented in Table 2.

This paper presents the determination of absorbed dose to water by application of four international protocols of dosimetry in radiotherapy: IAEA TRS-277 [10], AAPM TG-61 [9], IPEMB [12] and NCS-10 [11], for the same medium energy X-rays studied in calorimetry. A comparison between the new references in terms of absorbed dose to water at a $2 \mathrm{~cm}$ depth and their associated uncertainties established by water calorimetry at LNE-LNHB and the values determined by application of these protocols is made. Some correction factors had to be determined in order to be able to apply the protocols. Peixoto and Andreo [23] realized a theoretical intercomparison of the protocols applicable to medium energy X-ray beams and found a good agreement between the dosimetric data determined by protocols within 1-2 \%. In the same way of this study, Munck [24] proposed a intercomparison of the protocols using a NE2571 ionization chamber and a cylindrical Scanditronix/Wellhofer type FC65-G chamber. The difference with the present study is that the calibration factor of the cylindrical Scanditronix/Wellhofer type FC65-G chamber traceable to PTB, was given at $5 \mathrm{~cm}$ depth in water whereas the protocol requires a $2 \mathrm{~cm}$ depth. So, because of a use at a $2 \mathrm{~cm}$ depth Munck underlined that strict adherence to protocol can't be done and conclude the study leaning in favor of calibrating medium kilovoltage x-ray beams at $2 \mathrm{~cm}$ depth. The comparison here presented respond to this attempt and can directly be performed in the conditions described by protocols (at $2 \mathrm{~cm}$ depth in water).

\section{Materials}

\section{$\underline{\text { Tube high voltage }}$}

All irradiations were performed with the SEIFERT $320 \mathrm{kV}$ ISOVOLT HS tube high voltage of LNE-LNHB. Maximum high voltage is $320 \mathrm{kV}$ with a maximum power of $3 \mathrm{~kW}$. Maximum intensity is $30 \mathrm{~mA}$. The target of the tube is in tungsten and is angled to $20^{\circ}$ relative to the beam axis. The only inherent filtration of this tube is $3 \mathrm{~mm}$ of beryllium. In order to obtain the quality (HVL) requested, additional removable filters in aluminum and/or copper (with high purity over $99.9 \%$ ) are used. A primary circular collimation (diameter $55 \mathrm{~mm}$ ) is positioned at the exit of the tube at $21 \mathrm{~cm}$ from the target. A second squared collimation is used at $33 \mathrm{~cm}$ from the target $\left(66 \times 66 \mathrm{~mm}^{2}\right)$ in order to define the $10 \times 10 \mathrm{~cm}^{2}$ irradiation field size at $50 \mathrm{~cm}$ from the target. Measurements can be performed in terms of air kerma rate or absorbed dose rate to water because of the high stability of the power voltage of the tube.

\section{Absolute measurements of air kerma}

HVL measurements and references in terms of air kerma are determined thanks to the free air ionization chamber of the LNE-LNHB [25]. International comparisons were performed to assess this free air chamber and the good agreement with BIPM references (ratio of air kerma determined at BIPM by LNE-LNHB over the reference value of BIPM is $0.9999(\mathrm{u}=0.0039)$ for CCRI180 beam and $0.9980(\mathrm{u}=0.0039)$ for CCRI 250 beam [26]) allows us to be confident in the air kerma references and then into the calibration factor in terms of air kerma. Table 3 gives the characterization of the six beams here studied in terms of HVL.

References in terms of air kerma will be used to establish the air kerma calibration factors of the ionization chambers presented in the following section. These factors are necessary to apply the protocols based on references in terms of air kerma. The good knowledge of these references leads to reduce significantly the uncertainties. 


\section{Ionometric measurements}

The ionization chambers used to perform ionometric measurements were chosen following the IAEA-TRS277 protocol which recommends cylindrical ionization chamber with a cavity volume between 0.1 and $1 \mathrm{~cm}^{3}$. Two ionization chambers were selected: a NE2571 Farmer type $\left(0.6 \mathrm{~cm}^{3}\right)$ and a PTW31010 Semiflex $\left(0.125 \mathrm{~cm}^{3}\right)$.

In accordance with the AAPM TG-61 protocol, if the ionization chamber is not waterproof, waterproofing sleeve used should not leave an air space higher than $0.2 \mathrm{~mm}$ between the external wall of the chamber and the internal wall of the sleeve. Material of this sleeve should be in plastic. As the NE2571 ionization chamber is not waterproof, a waterproofing sleeve in PMMA was specially designed for this chamber in accordance with the recommendations above. The sleeve is also used for calibration in terms of air kerma.

NE2571 ionization chamber was chosen because of its stability and low energy dependence response in medium energy X-rays. Moreover, there is literature about the use of this type of ionization chamber in medium energy $\mathrm{X}$-rays [9, 24, 27-28].

PTW31010 ionization chamber was used because it is a waterproof chamber which volume is in the range recommended by the protocol.

We can note that source to chamber distance and wall thickness of these chambers are sufficient to be in transient electronic equilibrium conditions in that way no build up cap needs to be used.

\section{Phantom for ionometric measurements in water}

A $30 \times 30 \times 30 \mathrm{~cm}^{3}$ water phantom with wall in PMMA was used. The entrance window is a circular plate of quartz measuring $0.8 \mathrm{~mm}$ thickness and having a $12 \mathrm{~cm}$ diameter.

\section{Monte Carlo simulations}

Monte Carlo simulations of the device used for this study were realized at LNE-LNHB. Simulations of the tube high voltage, collimators and filtration were performed for the six beams studied with MCNPX code (using mcplib04 cross sections) [29].

\section{Methods: Dose determination by application of international dosimetric protocols based on references in terms of air kerma}

\subsection{Theory of the protocols based on air kerma references}

The methods followed in this study are the ones described in the four protocols: IAEA TRS-277 [10]; AAPM TG-61 [9] ; IPEMB [12] and NCS-10 [11]. Nevertheless, some correction factors needed to be determined or adapted to the conditions of this study. The theoretical approach is the same whatever the protocol considered. So, absorbed dose to water at a $2 \mathrm{~cm}$ depth is given by the general equation:

$$
D_{w, 2 c m}=M_{u} N_{K} k_{1} k_{2}\left[\left(\frac{\bar{\mu}_{e n}}{\rho}\right)_{w, a i r}\right]_{2 c m}
$$

with,

$M_{\mathrm{u}} \quad$ The corrected reading of the chamber. It is performed in water at $50 \mathrm{~cm}$ from the source at a $2 \mathrm{~cm}$ depth in water with a $10 \times 10 \mathrm{~cm}^{2}$ irradiation field (in the same conditions as calorimetric measurements). For medium energy, the effective point of measurement of the chamber is the geometrical center of the cavity [10]. So, the chamber is positioned with the center of the cavity at a $2 \mathrm{~cm}$ depth in water. Values are corrected from atmospheric conditions: temperature, pressure and humidity; and for recombination. Specific ionometric measurements were realized to determine recombination correction factor value applying the following equation taken ?? extracted 
from AAPM TG-61 protocol [9].

$$
k_{\text {rec }}=\frac{1-\left(\frac{V_{H}}{V_{L}}\right)^{2}}{\frac{M_{H}}{M_{L}}-\left(\frac{V_{H}}{V_{L}}\right)^{2}}
$$

The results lead us to consider for the six beams studied a recombination correction factor equals to unity with an associated uncertainty of $0.05 \%(\mathrm{k}=1)$.

Associated uncertainties of corrected readings in water are between $0.16 \%$ and $0.24 \%(\mathrm{k}=1)$ depending on the beam and the chamber considered.

$N_{\mathrm{K}} \quad$ The calibration factor in terms of air kerma. It is given by the following equation:

$$
N_{K}=\frac{K_{\text {air }}}{M_{\text {air }}}
$$

It is determined thanks to the free air ionization chamber of the laboratory for each beam and ionization chamber studied. Associated uncertainties of air kerma calibration factor is between $0.34 \%$ and $0.36 \%(\mathrm{k}=1)$ depending on the beam and chamber considered.

$\left[\left(\frac{\bar{\mu}_{e n}}{\rho}\right)_{w, a i r}\right]_{2 c m}$

The ratio of averaged mass energy absorption coefficient for water to air. The values

used in this study are based on Hubbell and Seltzer's cross-sections [30-31] weighted by beams spectra determined by Monte-Carlo simulations of the device. The associated uncertainty is $2 \%$ on this factor.

$k_{1} \quad$ The factor which corrects for the difference of spectral distribution at the surface of the cavity between the calibration in air and the use at a $2 \mathrm{~cm}$ depth in water.

$k_{2} \quad$ The factor which corrects for the non equivalent water of the ionization chamber when in the user's beam.

All of the four protocols applied in this study are based on this theoretical model. The difference lies in the name and the determination of the correction factors. The same corrected reading of the chambers in water, air kerma calibration factors and averaged mass energy absorption coefficient for water to air will be used to apply these different protocols. So, a description of the own factors of each protocols and their determination will be presented in the following sections.

\subsection{The IAEA TRS 277 protocol}

In this protocol, absorbed dose to water is given by the following equation

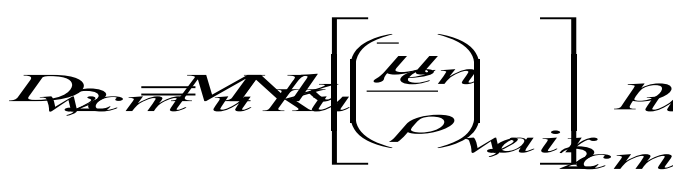


$\mathrm{D}_{\mathrm{w}, 2 \mathrm{~cm}}, M_{\mathrm{u}}, N_{\mathrm{K}},\left[\left(\frac{\bar{\mu}_{e n}}{\rho}\right)_{w, a i r}\right]_{2 c m}$ are the same as previously described.

$k_{u}$ (equals to $k_{1}$ from theoretical approach) is the factor to account for variations in spectral distribution of X-ray beams used for the ionization chamber calibration free in air and that used by the user at a $2 \mathrm{~cm}$ depth in water. In accordance with the protocol, there are two components:

The first one takes into account the difference of beam quality between the beam used for calibration at standard laboratory and the one of the user. In this study the user and calibration beams are strictly the same so this first part of the factor equals to unity.

The second one corrects from the difference of the chamber response induced by the difference in spectral distribution when the chamber is calibrated in air and when used at a $2 \mathrm{~cm}$ depth in water (reference conditions). No values are proposed for this correction factor. The user has to check this variation not exceed $2.0 \%$ and in this case is allowed to use a correction factor equals to unity with an associated uncertainty of $2.0 \%(\mathrm{k}=1)$.

In order to determine the variation, Monte-Carlo simulations of the device were used. The spectral distribution of the six beams studied at a $2 \mathrm{~cm}$ depth in water $(50 \mathrm{~cm}$ from the source with a $10 \times 10 \mathrm{~cm}^{2}$ irradiation field) were calculated. Then, Spekcalc and XCOMP5 programs [32-33] were used in order to generate spectral distribution in air whose characteristics (HVL, mean energy, general allure) match the ones of the distribution previously modeled. Spekcalc and XCOMP5 give us the filtration to use in order to generate the beams experimentally. So, we obtained an in air beam « equivalent» to the one at a $2 \mathrm{~cm}$ depth in water for each beams of interest (Table 4). Then we realized these equivalent beams experimentally and determined the calibration factor in terms of air kerma for the two ionization chambers used. The ratio of the calibration factors in terms of air kerma of the real beam to the equivalent one for each beam assessed is the factor wished. Results are given Table 5 .

For each beam of interest and for the two ionization chambers the difference is below $2.0 \%$ allowing us to choose a correction factor equals to unity with an associated uncertainty of $2.0 \%$ according to the protocol $(\mathrm{k}=1)$.

$p_{\mathrm{u}}$ is the correction factor which takes into account dosimetric perturbations.

Ma and Nahum [34] proposed a method to determine this correction factor. This is the one used in AAPM TG-61 protocol and called $p_{\text {disp }}$ and which will be discussed in the following section.

A series of values is proposed by the IAEA TRS-277 protocol. They were applied. Nevertheless the exact definition of this factor and its mean of determination are not well described in the protocol. Users have to pay attention to consider the revised values of the coefficient and not the first ones. Associated uncertainties to these values is $2.0 \%(\mathrm{k}=1)$.

\section{3. $\quad$ The AAPM TG-61 protocol}

In this protocol, absorbed dose to water is given by the following equation

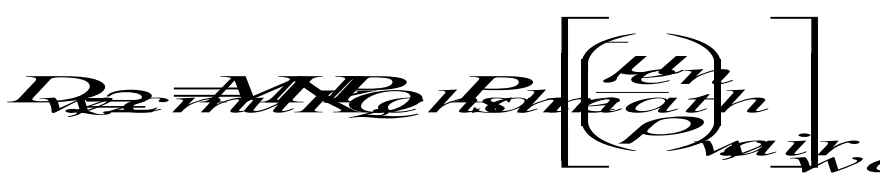

We decided to use the in-phantom method for all the beams in order to be consistent with the other protocols even if this method is not recommended below $100 \mathrm{kV}$ in this protocol.

As usual, $M_{\mathrm{u}}, N_{\mathrm{K}},\left[\left(\frac{\bar{\mu}_{e n}}{\rho}\right)_{w, a i r}\right]_{2 c m}$ are the same as previously described. 
The global correction factor is defined as follows:

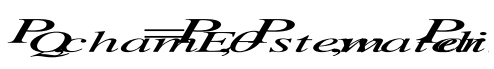

with,

$P_{E, \theta} \quad$ the factor to take into account the change in the air kerma calibration factor due to the change of spectral energy and angular distribution of the beams.

$P_{\text {stem,water }}$ the factor to take into account stem influence on the ionization chamber readings (influence when ionization chambers is calibrated in air and when used in water).

$P_{\text {dis }} \quad$ the factor to take into account air kerma change at the point of measurement due to water displacement induced by the cavity volume, its wall and waterproofing sleeve if present.

Values of $P_{\mathrm{Q} \text {,cham }}$ are given in the protocols for a NE2571 ionization chamber calibrated in terms of air kerma without proofing sleeve but used at a $2 \mathrm{~cm}$ depth in water with a proofing sleeve. In this study, the proofing sleeve was used both for air kerma calibration and measurements in water so the factor can't be directly applied. The factor which needs to be determined has to take into account the displacement of water induced by the presence or not of the sleeve. It is defined as the ratio of the displacement factor $P_{\text {dis }}$ when the sleeve is present ( $\left.k_{\text {dis,with_sleeve }}\right)$ to the value when no sleeve is used ( $k_{\text {dis,without_sleeve). }}$ It is given by the following equation:

\section{Kaiswithleeve \\ Kaiswithoultee}

These values were calculated thanks to Monte-Carlo simulations applying the method described by $\mathrm{Ma}$ and Nahum [34]. This factor is the ratio of the kerma in water at the reference depth in the medium none disturbed to the kerma in a low density water cavity (in fact density of air) in water. Volume considered is the one of the ionization chamber with its wall and the sleeve or not depending on the factor calculated. Uncertainties associated to the ratio of factors are $0.08 \%$.

Results of calculated factors are presented Figure 2. A good agreement is found between the values calculated without sleeve and the values determined by Seuntjens [35].

Thanks to Monte-Carlo simulations this factor was also adapted to application of the protocol for the PTW31010 ionization chamber.

The equation to determine absorbed dose to water by application of the TG-61 protocol is finally:

$$
D_{w, z=2 c m}=M N_{k} P_{Q, c h a m} \frac{k_{\text {dis,avec_capot }}}{k_{\text {dis,sans_capot }}}\left[\left(\frac{\overline{\mu_{e n}}}{\rho}\right)_{w, \text { air }}\right]_{\text {water }}
$$

\subsection{The IPEMB and NCS-10 protocol}

The general equation to determine absorbed dose to water is given by the following equation: 


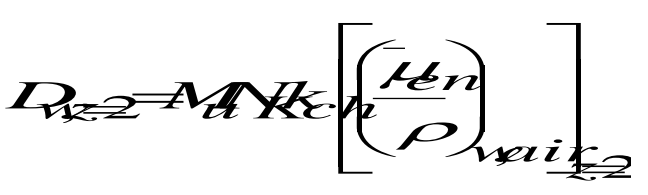

In these two protocols a global correction factor is applied. In the IPEMB, a series of values is proposed. This one is based on studies from Rosser, Seuntjens, Ma and Nahum [27, 34, 36] . The uncertainties associated to this correction factor are also given and are $3.0 \%$. Whereas this factor was determined for NE2561 ionization chamber (waterproof), the protocol allows application to NE2571 ionization chamber without supplementary uncertainties. This approximation seems right because of the small ?? few difference in terms of volume and construction between these two chambers.

About the $k_{\mathrm{ch}}$ values by application of the NCS-10 protocol, these ones were determined and described in the studies of Seuntjens and Verhaegen. Standard uncertainty associated is $0.9 \%$.

\section{Results and discussion}

Figure 3 gives the comparison of absorbed dose rate to water determined by application of the four protocols: IAEA TRS-277; AAPM; TG-61; IPEMB and NCS-10 to the six beams of interest with the two ionization chambers (NE2571 and PTW31010). For each beams, results are normalized to the values obtained by application of the IAEA TRS-277 protocol to the NE2571 ionization chamber.

Uncertainty budgets for the application of the protocols to the six beams for the NE2571 ionization chamber and the PTW31010 ionization chamber are given in Table 6, Table 7, Table 8 and Table 9 respectively for the protocols IAEA TRS-277, AAPM TG-61, IPEMB and NCS-10. Uncertainties on corrected readings include uncertainty on position, current, atmospheric conditions and recombination factor. Additional uncertainties relative to the influence of the stem in air and in water and to the sleeve are taken into account. Choice was made to apply a correction factor equals to unity for the influence of stem and sleeve but to add uncertainties in the uncertainties budget. They were determined thanks to experimental measurements with an additional sleeve and stem.

First of all, we can say that variation of calibration factor in terms of air kerma with half value layer (HVL) is in good agreement with results obtained by Seuntjens [37]. Indeed calibration correction values decrease with HVL. We can also say that the use of a PMMA waterproofing sleeve don't need supplementary correction to apply, because the NE2571 ionization chamber is calibrated in air in terms of air kerma with this sleeve.

Results obtained by application of the four protocols: IAEA TRS 277; AAPM TG-61; IPEMB and NCS-10 to the two ionization chambers are in good agreement. Results obtained for the NE2571 are under uncertainties which are between and with a maximum deviation of. Results obtained for the PTW31010 are under uncertainties which are between and with a maximum deviation of. Standard uncertainties variation is due to the protocols and not to the ionization chambers. Indeed, the highest uncertainties are systematically obtained by application of the IAEA TRS 277 protocol. It's not surprising because of the associated uncertainties for the correction factors pu and ku. For each beam, no significant difference is observed between the two ionization chambers whatever the protocol used. Uncertainties around $3 \%$ by application of the protocols were also found by Munck. They also concluded to compatibility of results from protocols concerning the "in-phantom method" which was applied here.

Nevertheless, several problems intrinsic to the application of these protocols can be underlined. Indeed, whatever the protocol used, the theoretical method being the same, absorbed dose to water determination is indirect and can lead to mistakes. Moreover, some uncertainties are not well known, difficult to define because of the lack of data and can be quite high (the mass absorption coefficient ratio for example). Some correction factors are not well defined: for example the $k_{\mathrm{u}}$ 
factor from the IAEA TRS 277 protocol whose value was revised from 1.10 to 1.03 between the two version protocols. We can also say that some correction factors $\left(k_{\mathrm{u}}\right.$ from the IAEA TRS-277 protocol for example) are not determinable in a laboratory or hospital which doesn't have primary standard detectors.

Figure 4 gives the comparison between all the results from application of the protocols with calorimetry values. Results are normalized to the calorimetrics absorbed dose rate values for each beam of interest. Results in terms of absorbed dose to water obtained by water calorimetry and by application of the protocols based on calibration factors in terms of air kerma were also found in good agreement. A maximum deviation of $1.2 \%$ was registered with a water calorimetry associated uncertainty of $0.9 \%$ and a protocol associated uncertainty around $2.5 \%$. But, we have to note that uncertainties associated to the application of the protocols are high.

Absorbed dose to water calibration factor can be determined thanks to the absorbed dose to water values. The general equation is:

$$
N_{D, w}=\frac{D_{w}}{M_{u, w}}
$$

The comparison realized about calibration factors in terms of absorbed dose to water is presented Figure 5 for the NE2571 ionization chamber and Figure 6 for the PTW31010 ionization chamber. Results are also in good agreement with values under uncertainties. Calibration factors determined from absorbed dose to water obtained by dosimetric protocols in terms of air kerma are in fact the air kerma calibration factor multiply by the different correction factors. So the difference of variation with energy of these $N_{\mathrm{D} \text {,w }}$ is only due to the correction factors. For better reading of the figures, choice was made to not represent uncertainties associated to the $N_{\mathrm{D} \text {,w }}$ determined by application of the protocols. Nevertheless, Table 10 and Table 11, sum up uncertainty values associated to the $N_{\mathrm{D}, \mathrm{w}}$, for the NE2571 ionization chamber and PTW31010 ionization chamber respectively. A better agreement with calorimetry is obtained for the NE2571 ionization chamber than for the PTW31010 ionization chamber. Moreover, for the two chambers, it appears that only the calibration factor established by application of AAPM TG-61 protocol seems to follow the variation of the calibration factor determined from calorimetric references.

\section{Conclusion}

New references in terms of absorbed dose to water for medium energy X-rays had just been established at LNE-LNHB thanks to water calorimetry at a $2 \mathrm{~cm}$ depth in the reference conditions described by protocols. Four protocols based on references in terms of air kerma were applied to two ionization chambers (NE2571 and PTW31010) to six medium energy X-rays beams chosen among norms and protocols in the range of interest $(80 \mathrm{kV}$ to $300 \mathrm{kV}$ in accordance with international dosimetric protocols). The comparison performed between protocols shows a good agreement of them, whatever the beam or the chamber used. In the same way, the comparison between absorbed dose rates to water obtained by water calorimetry and by application of the protocols based on calibration factors in terms of air kerma were also found in good agreement. A maximum deviation, between these methods, of $2.1 \%$ was registered with a water calorimetry associated uncertainty below $0.9 \%(\mathrm{k}=1)$ and associated uncertainties around $2.5 \%(\mathrm{k}=1)$ for the application of the protocols. So, despite of the good agreement, a significant reduction of uncertainties on absorbed dose rate to water is obtained using water calorimetry.

These new references in terms of absorbed dose to water will be useful for physicists who want to apply protocols requiring references in terms of absorbed dose to water like the IAEA TRS-398 
protocol. Until now, it was not possible to strictly apply it because no absorbed dose to water references established at a $2 \mathrm{~cm}$ depth existed. Application of protocols using references in terms of absorbed dose to water will allow reducing significantly the uncertainties (factor of 2) and limiting the potential mistakes in the determination of the absorbed dose to water which is fastidious when applying international dosimetric protocols using references in terms of air kerma. Before being transferred to users, these references will be compared to the ones obtained by counterparts' laboratories. This comparison is planned to be realized in the framework of the HLT09 European project.

1. Pergolizzi, S., A. Santacaterina, M. Gaeta, and A. Blandino, Kaposi's sarcoma in young patients treated with orthovoltage irradiation and having a minimum follow-up of forty-six years. Tumori, 2009. 95(3): p. 325-328.

2. Wolstenholme, V., The role of kilovoltage X-rays in the treatment of skin cancers. European Oncological disease, 2006.

3. Askoxylakis, V., Radiotherapy of skin cancers. Expert Review of Dermatology, 2010. 5(2): p. 173-181.

4. Barnes, E.A., D. Breen, S. Culleton, L. Zhang, J. Kamra, M. Tsao, and J. Balogh, Palliative Radiotherapy for Non-melanoma Skin Cancer. Clinical Oncology, 2010. 22(10): p. 844-849.

5. Evans, P.A., A.J. Moloney, and P.J. Mountford, Performance assessment of the Gulmay D3300 kilovoltage X-ray therapy unit. British Journal of Radiology, 2001. 74(882): p. 537547.

6. D'Alimonte, L., E. Sinclair, and S. Seed, Orthovoltage energies for palliative care in the 21 st century: Is there a need? Radiography, 2011. 17(1): p. 84-87.

7. Goblirsch, M., Radiation treatment decreases bone cancer pain, osteolysis and tumor size. Radiation research, 2004. 161(2): p. 228-234.

8. Andreo, P., Absorbed dose determination in external beam radiotherapy: An international code of practice for dosimetry based on standards of absorbed dose to water; technical reports series No. 398. 2006.

9. Chair, C.-M.M., C.W. Coffey, L.A. DeWerd, C. Liu, R. Nath, S.M. Seltzer, and J.P. Seuntjens, AAPM protocol for 40--300 kV x-ray beam dosimetry in radiotherapy and radiobiology. Medical Physics, 2001. 28(6): p. 868-893.

10. AIEA, Absorbed dose determination in photon and electron beams: an international code of practice. Technical Reports Series n²77, 1997.

11. NCS, N.C.v.S., Dosimetry for low and medium energy $x$-rays: a code of practice in radiotherapy and radiobiology. NCS Report 10, 1997.

12. Klevenhagen, S.C., R.J. Aukett, R.M. Harrison, C. Moretti, A.E. Nahum, and K.E. Rosser, The IPEMB code of practice for the determination of absorbed dose for $x$-rays below $300 \mathrm{kV}$ generating potential (0.035 mm Al-4 mm Cu HVL; 10-300 kV generating potential). Physics in Medicine and Biology, 1996. 41(12): p. 2605-2625.

13. ISO, Rayonnements $X$ et gamma de référence pour l'étalonnage des dosimètres et des débitmètres, et pour la détermination de leur réponse en fonction de l'énergie des photons - Partie 1: Caractéristiques des rayonnements et méthodes de production. ISO4037-1, 1996.

14. IEC, Medical diagnostic X-ray equipment - Radiation conditions for use in the determination of characteristics. IEC61267, 2005.

15. BIPM, Qualités de rayonnement. CCEMRI(I), 1972(R15).

16. Ross, C.K. and N.V. Klassen, Water calorimetry for radiation dosimetry. Physics in Medicine and Biology, 1996. 41(1): p. 1-29.

17. DuSautoy, A.R., The UK primary standard calorimeter for photon-beam absorbed dose measurement. Physics in Medicine and Biology, 1996. 41(1): p. 137-151.

18. Guerra, A.S., R.F. Laitano, and M. Pimpinella, Characteristics of the absorbed dose to water standard at ENEA. Physics in Medicine and Biology, 1996. 41(4): p. 657-674.

19. Domen, S.R., ABSORBED DOSE WATER CALORIMETER. Medical Physics, 1980. 7(2): p. 
157-159.

20. Kubo, H., WATER CALORIMETRIC DETERMINATION OF ABSORBED DOSE IN COMPARISON TO IONIZATION-CHAMBER DETERMINATION. Medical Physics, 1983. 10(4): p. 538-538.

21. Osborne, Measurements of Heat Capacity and Heat of Vaporization of Water in the Range of $0^{\circ} \mathrm{C}$ to $100^{\circ} \mathrm{C}$. Research NBS, 1939 .

22. Ross, C.K., N.V. Klassen, K.R. Shortt, and G.D. Smith, A DIRECT COMPARISON OF WATER CALORIMETRY AND FRICKE DOSIMETRY. Physics in Medicine and Biology, 1989. 34(1): p. 23-42.

23. Peixoto, J.G.P. and P. Andreo, Determination of absorbed dose to water in reference conditions for radiotherapy kilovoltage $x$-rays between 10 and $300 \mathrm{kV}$ : a comparison of the data in the IAEA, IPEMB, DIN and NCS dosimetry protocols. Physics in Medicine and Biology, 2000. 45(3): p. 563-575.

24. Kilovoltage $x$-ray dosimetry-an experimental comparison between different dosimetry protocols. Phys. Med. Biol., 2008. 53(16): p. 4431.

25. Ksouri, W., Etude et réalisation des références dosimétriques nationales en termes de kerma dans l'air pour les faisceaux de rayons $X$ de basses et moyennes énergies. Rapport CEA-R6209, 2009.

26. Burns, D.T., C. Kessler, M. Denoziere, and W. Ksouri, Key comparison BIPM.RI(I)-K3 of the air-kerma standards of the LNE-LNHB, France and the BIPM in medium-energy $x$-rays. Metrologia, 2008. 45(1A): p. 06004.

27. Seuntjens, J., H. Thierens, and U. Schneider, Correction factors for a cylindrical ionization chamber used in medium-energy X-ray beams. Physics in Medicine and Biology, 1993. 38(6): p. 805.

28. Ma, C.-M. and A.E. Nahum, Monte Carlo calculated stem effect corrections for NE2561 and NE2571 chambers in medium-energy X-ray beams. Physics in Medicine and Biology, 1995. 40(1): p. 63.

29. Pelowitz, MCNPX User's Manual Version 2.5.0. Los Alamos National Laboratory report LA-CP-05-0369, 2005.

30. Hubbell, Photon mass attenuation and energy-absorption coefficients. The International Journal of Applied Radiation and Isotopes, 1982. 33(11): p. 1269-1290.

31. Seltzer, H.a., Tables of x-ray mass attenuation coefficients and mass energy-absorption coefficients $1 \mathrm{keV}$ to $20 \mathrm{MeV}$ for elements $Z=1$ to 92 and 48 additional substances of dosimetric interest. Report No. NISTIR 5632, NIST, Gaithersburg, MD, 1995.

32. Poludniowski, G., G. Landry, F. DeBlois, P.M. Evans, and F. Verhaegen, SpekCalc: a program to calculate photon spectra from tungsten anode $x$-ray tubes. Physics in Medicine and Biology, 2009. 54(19): p. N433-N438.

33. Nowotny, XCOMP5, Program for calculating diagnostic X-ray spectra. Roefo. Fortschr.Geb. Roentgenstr. Nuklearmed., 1985. 142: p. 685-689.

34. Ma, C.M. and A.E. Nahum, CALCULATIONS OF ION-CHAMBER DISPLACEMENT EFFECT CORRECTIONS FOR MEDIUM-ENERGY X-RAY DOSIMETRY. Physics in Medicine and Biology, 1995. 40(1): p. 45-62.

35. Seuntjens, J. and F. Verhaegen, Dependence of overall correction factor of a cylindrical ionization chamber on field size and depth in medium-energy $x$-ray beams. Medical Physics, 1996. 23(10): p. 1789-1796.

36. Rosser, K.E., Measurement of absorbed dose to water for medium energy X-rays. Measurement of absorbed dose to water for medium energy X-rays, 1992.

37. Seuntjens, J., H. Thierens, A. Vanderplaetsen, and O. Segaert, DETERMINATION OF ABSORBED DOSE TO WATER WITH IONIZATION CHAMBERS CALIBRATED IN FREE AIR FOR MEDIUM-ENERGY X-RAYS. Physics in Medicine and Biology, 1988. 33(10): p. 1171-1185. 
Table 1 : Kilovoltage medium energy $X$-ray beams studied

\begin{tabular}{cccc}
\hline Beam & $\begin{array}{c}\text { High voltage } \\
(\mathrm{kV})\end{array}$ & $\begin{array}{c}\text { Additional filtration suggested } \\
\text { by norms and protocols }(\mathrm{mm})\end{array}$ & HVL \\
\hline IEC 61267 RQR6 & 80 & $2.50 \mathrm{Al}$ & $3.01 \mathrm{~mm} \mathrm{Al}$ \\
IEC 61267 RQR9 & 120 & $2.50 \mathrm{Al}$ & $5.00 \mathrm{~mm} \mathrm{Al}$ \\
IEC 61267 RQR10 & 150 & $2.50 \mathrm{Al}$ & $6.57 \mathrm{~mm} \mathrm{Al}$ \\
CCRI 180 & 180 & $4.06 \mathrm{Al}+0.51 \mathrm{Cu}$ & $1.00 \mathrm{~mm} \mathrm{Cu}$ \\
CCRI 250 & 250 & $4.02 \mathrm{Al}+1.72 \mathrm{Cu}$ & $2.50 \mathrm{~mm} \mathrm{Cu}$ \\
ISO 4037 H300 & 300 & $4.00 \mathrm{Al}+2.50 \mathrm{Cu}$ & $3.40 \mathrm{~mm} \mathrm{Cu}$ \\
\hline \hline
\end{tabular}

Table 2 : Absorbed dose rate to water determined by water calorimetry for the six beams studied. Associated uncertainties are given at $k=1$.

\begin{tabular}{|c|c|c|}
\hline Beam & $\begin{array}{l}\text { Absorbed dose rate to water } \\
\text { (at } 2 \mathrm{~cm} \text { depth } ; \text { DSC }=50 \mathrm{~cm} ; \\
10 \times 10 \mathrm{~cm}^{2} \text { field size) determined } \\
\text { by water calorimetry }\left(\mathrm{Gy} \cdot \mathrm{min}^{-1}\right)\end{array}$ & $\begin{array}{c}\mathrm{u} \\
(\%)\end{array}$ \\
\hline $\begin{array}{c}\text { IEC } 61267 \\
\text { RQR6 }\end{array}$ & 0.329 & 0.72 \\
\hline $\begin{array}{c}\text { IEC } 61267 \\
\text { RQR9 }\end{array}$ & 0.356 & 0.71 \\
\hline $\begin{array}{c}\text { IEC } 61267 \\
\text { RQR10 }\end{array}$ & 0.534 & 0.64 \\
\hline CCRI180 & 0.424 & 0.56 \\
\hline CCRI250 & 0.536 & 0.49 \\
\hline $\begin{array}{c}\text { ISO4037 } \\
\text { H300 }\end{array}$ & 0.405 & 0.55 \\
\hline
\end{tabular}

Table 3 : Characterization of the six beams studied in terms of HVL

\begin{tabular}{ccccccc}
\hline \hline Beam & $\begin{array}{c}\text { High } \\
\text { voltage } \\
(\mathrm{kV})\end{array}$ & $1^{\text {st }} \mathrm{HVL}($ norms $)$ & Tolerance & $1^{\text {st }} \mathrm{HVL}(\mathrm{exp})$ & $\mathrm{u}(\%)$ & Difference $1^{\text {st }} \mathrm{HVL}(\%)$ \\
\hline $\begin{array}{c}\text { IEC 61267 } \\
\text { RQR6 }\end{array}$ & 80 & $3.01 \mathrm{~mm} \mathrm{Al}$ & $\pm 0.1 \mathrm{~mm}$ & $3.00 \mathrm{~mm} \mathrm{Al}$ & \pm 1.0 & -0.3 \\
$\begin{array}{c}\text { IEC 61267 } \\
\text { RQR9 }\end{array}$ & 120 & $5.00 \mathrm{~mm} \mathrm{Al}$ & $\pm 0.1 \mathrm{~mm}$ & $4.99 \mathrm{~mm} \mathrm{Al}$ & \pm 1.0 & -0.2 \\
$\begin{array}{c}\text { IEC 61267 } \\
\text { RQR10 }\end{array}$ & 150 & $6.57 \mathrm{~mm} \mathrm{Al}$ & $\pm 0.1 \mathrm{~mm}$ & $6.55 \mathrm{~mm} \mathrm{Al}$ & \pm 1.0 & -0.3 \\
CCRI 180 & 180 & $0.98 \mathrm{~mm} \mathrm{Cu}$ & - & $0.98 \mathrm{~mm} \mathrm{Cu}$ & \pm 1.0 & 0.0 \\
$\begin{array}{c}\text { CCRI 250 } \\
\text { ISO 4037 }\end{array}$ & 250 & $2.48 \mathrm{~mm} \mathrm{Cu}$ & - & $2.48 \mathrm{~mm} \mathrm{Cu}$ & \pm 1.0 & 0.0 \\
H300 & 300 & $3.40 \mathrm{~mm} \mathrm{Cu}$ & $\pm 5 \%$ & $3.40 \mathrm{~mm} \mathrm{Cu}$ & \pm 1.0 & 0.0 \\
\hline \hline
\end{tabular}


Table 4 : Characteristics of the water equivalent beam in terms of tube high voltage and filtration

Water equivalent beam characteristics

(high voltage; filtration)

\begin{tabular}{cc}
\hline IEC 61267 RQR6 & $70 \mathrm{kV} ; 4 \mathrm{~mm} \mathrm{Al}$ \\
IEC 61267 RQR9 & $96 \mathrm{kV} ; 0.14 \mathrm{~mm} \mathrm{Cu}$ \\
IEC 61267 RQR10 & $100 \mathrm{kV} ; 6.8 \mathrm{~mm} \mathrm{Al}$ \\
CCRI 180 & $140 \mathrm{kV} ; 4 \mathrm{~mm} \mathrm{Al}+0.2 \mathrm{~mm} \mathrm{Cu}$ \\
CCRI 250 & $250 \mathrm{kV} ; 4 \mathrm{~mm} \mathrm{Al}+0.4 \mathrm{~mm} \mathrm{Cu}$ \\
ISO 4037 H300 & $300 \mathrm{kV} ; 4 \mathrm{~mm} \mathrm{Al}+0.4 \mathrm{~mm} \mathrm{Cu}$ \\
\hline \hline
\end{tabular}

Table $5: k_{u}$ factors determined for each beam of interest for the two ionization chambers used

\begin{tabular}{ccc}
\hline \hline Beam & NE2571 & $\mathrm{k}_{\mathrm{u}}$ \\
\hline IEC 61267 RQR6 & 0.994 & PTW31010 \\
IEC 61267 RQR9 & 1.014 & 1.020 \\
IEC 61267 RQR10 & 0.990 & 1.012 \\
CCRI180 & 1.005 & 0.988 \\
CCRI250 & 1.010 & 1.010 \\
ISO4037 H300 & 1.017 & 0.999 \\
\hline \hline
\end{tabular}

Table 6 : Uncertainties (in \%) on the application of the IAEA TRS-277 protocol to the NE2571 ionization chamber (a) and to the PTW31010 (b).

\begin{tabular}{|c|c|c|c|c|c|c|c|c|c|c|c|c|}
\hline & \multicolumn{2}{|c|}{$\begin{array}{c}\text { IEC } 61267 \\
\text { RQR6 }\end{array}$} & \multicolumn{2}{|c|}{$\begin{array}{c}\text { IEC } 61267 \\
\text { RQR9 }\end{array}$} & \multicolumn{2}{|c|}{$\begin{array}{c}\text { IEC } 61267 \\
\text { RQR10 }\end{array}$} & \multicolumn{2}{|c|}{ CCRI180 } & \multicolumn{2}{|c|}{ CCRI250 } & \multicolumn{2}{|c|}{$\begin{array}{c}\text { ISO4037 } \\
\text { H300 }\end{array}$} \\
\hline & $\mathrm{a}$ & $\mathrm{b}$ & $\mathrm{a}$ & b & $\mathrm{a}$ & b & $\mathrm{a}$ & b & $\mathrm{a}$ & $\mathrm{b}$ & $\mathrm{a}$ & b \\
\hline $\begin{array}{l}\text { Corrected } \\
\text { reading }\end{array}$ & 0.24 & 0.17 & 0.19 & 0.17 & 0.17 & 0.17 & 0.16 & 0.17 & 0.16 & 0.17 & 0.19 & 0.18 \\
\hline $\begin{array}{l}\text { Air kerma } \\
\text { calibration } \\
\text { factor }\end{array}$ & 0.34 & 0.34 & 0.34 & 0.34 & 0.34 & 0.34 & 0.35 & 0.35 & 0.34 & 0.34 & 0.35 & 0.35 \\
\hline$k_{\mathrm{u}}$ & 2.0 & 2.0 & 2.0 & 2.0 & 2.0 & 2.0 & 2.0 & 2.0 & 2.0 & 2.0 & 2.0 & 2.0 \\
\hline$\left[\left(\frac{\bar{\mu}_{e n}}{\rho}\right)_{w, a i r}\right]_{2 c m}$ & 2.0 & 2.0 & 2.0 & 2.0 & 2.0 & 2.0 & 2.0 & 2.0 & 2.0 & 2.0 & 2.0 & 2.0 \\
\hline$p_{\mathrm{u}}$ & 2.0 & 2.0 & 2.0 & 2.0 & 2.0 & 2.0 & 2.0 & 2.0 & 2.0 & 2.0 & 2.0 & 2.0 \\
\hline stem & 0.12 & 0.24 & 0.15 & 0.23 & 0.10 & 0.19 & 0.13 & 0.24 & 0.10 & 0.24 & 0.13 & 0.21 \\
\hline sleeve & 0.30 & - & 0.30 & - & 0.30 & - & 0.30 & - & 0.30 & - & 0.30 & - \\
\hline Total & 3.50 & 3.51 & 3.50 & 3.51 & 3.50 & 3.50 & 3.50 & 3.51 & 3.50 & 3.51 & 3.50 & 3.51 \\
\hline
\end{tabular}


Table 7 : Uncertainties (in \%) on the application of the AAPM TG-61 protocol to the NE2571 ionization chamber (a) and to the PTW31010 (b).

\begin{tabular}{|c|c|c|c|c|c|c|c|c|c|c|c|c|}
\hline & \multicolumn{2}{|c|}{$\begin{array}{l}\text { IEC } 61267 \\
\text { RQR6 }\end{array}$} & \multicolumn{2}{|c|}{$\begin{array}{c}\text { IEC } 61267 \\
\text { RQR9 }\end{array}$} & \multicolumn{2}{|c|}{$\begin{array}{c}\text { IEC } 61267 \\
\text { RQR10 }\end{array}$} & \multicolumn{2}{|c|}{ CCRI180 } & \multicolumn{2}{|c|}{ CCRI250 } & \multicolumn{2}{|c|}{$\begin{array}{c}\text { ISO4037 } \\
\text { H300 }\end{array}$} \\
\hline & $\mathrm{a}$ & b & $\mathrm{a}$ & b & $\mathrm{a}$ & $b$ & $\mathrm{a}$ & b & $\mathrm{a}$ & b & $\mathrm{a}$ & b \\
\hline $\begin{array}{l}\text { Corrected } \\
\text { reading }\end{array}$ & 0.24 & 0.17 & 0.19 & 0.17 & 0.17 & 0.17 & 0.16 & 0.17 & 0.16 & 0.17 & 0.19 & 0.18 \\
\hline $\begin{array}{c}\text { Air kerma } \\
\text { calibration } \\
\text { factor }\end{array}$ & 0.34 & 0.34 & 0.34 & 0.34 & 0.34 & 0.34 & 0.35 & 0.35 & 0.34 & 0.34 & 0.35 & 0.35 \\
\hline$P_{Q, \text { cham }}$ & 1.5 & 1.5 & 1.5 & 1.5 & 1.5 & 1.5 & 1.5 & 1.5 & 1.5 & 1.5 & 1.5 & 1.5 \\
\hline$\left.\left(\frac{\bar{\mu}_{e n}}{\rho}\right)_{w, a i r}\right|_{2 c m}$ & 1.5 & 1.5 & 1.5 & 1.5 & 1.5 & 1.5 & 1.5 & 1.5 & 1.5 & 1.5 & 1.5 & 1.5 \\
\hline$k_{\text {dis,total }}$ & 2.0 & 2.0 & 2.0 & 2.0 & 2.0 & 2.0 & 2.0 & 2.0 & 2.0 & 2.0 & 2.0 & 2.0 \\
\hline stem & 0.12 & 0.24 & 0.15 & 0.23 & 0.10 & 0.19 & 0.13 & 0.24 & 0.10 & 0.24 & 0.13 & 0.21 \\
\hline sleeve & 0.30 & - & 0.30 & - & 0.30 & - & 0.30 & - & 0.30 & - & 0.30 & - \\
\hline Total & 2.19 & 2.17 & 2.19 & 2.17 & 2.18 & 2.17 & 2.18 & 2.17 & 2.18 & 2.17 & 2.18 & 2.17 \\
\hline
\end{tabular}

Table 8 : Uncertainties (in \%) on the application of the IPEMB protocol to the NE2571 ionization chamber (a) and to the PTW31010 (b).

\begin{tabular}{|c|c|c|c|c|c|c|c|c|c|c|c|c|}
\hline & \multicolumn{2}{|c|}{$\begin{array}{c}\text { IEC } 61267 \\
\text { RQR6 }\end{array}$} & \multicolumn{2}{|c|}{$\begin{array}{c}\text { IEC } 61267 \\
\text { RQR9 }\end{array}$} & \multicolumn{2}{|c|}{$\begin{array}{c}\text { IEC } 61267 \\
\text { RQR10 }\end{array}$} & \multicolumn{2}{|c|}{ CCRI180 } & \multicolumn{2}{|c|}{ CCRI250 } & \multicolumn{2}{|c|}{$\begin{array}{c}\text { ISO4037 } \\
\text { H300 }\end{array}$} \\
\hline & $\mathrm{a}$ & $\mathrm{b}$ & $\mathrm{a}$ & $\mathrm{b}$ & $\mathrm{a}$ & $\mathrm{b}$ & $\mathrm{a}$ & $\mathrm{b}$ & $\mathrm{a}$ & $\mathrm{b}$ & $\mathrm{a}$ & $\mathrm{b}$ \\
\hline $\begin{array}{l}\text { Corrected } \\
\text { reading }\end{array}$ & 0.24 & 0.17 & 0.19 & 0.17 & 0.17 & 0.17 & 0.16 & 0.17 & 0.16 & 0.17 & 0.19 & 0.18 \\
\hline $\begin{array}{c}\text { Air kerma } \\
\text { calibration } \\
\text { factor }\end{array}$ & 0.34 & 0.34 & 0.34 & 0.34 & 0.34 & 0.34 & 0.35 & 0.35 & 0.34 & .34 & 0.35 & 0.35 \\
\hline$k_{c h}$ & 3.0 & 3.0 & 3.0 & 3.0 & 3.0 & 3.0 & 3.0 & 3.0 & 3.0 & 3.0 & 3.0 & 3.0 \\
\hline$\left.\left(\frac{\bar{\mu}_{e n}}{\rho}\right)_{w, a i r}\right]_{2 c}$ & 1.0 & 1.0 & 1.0 & 1.0 & 1.0 & 1.0 & 1.0 & 1.0 & 1.0 & 1.0 & 1.0 & 1.0 \\
\hline stem & 0.12 & 0.24 & 0.15 & 0.23 & 0.10 & 0.19 & 0.13 & 0.24 & 0.10 & 0.24 & 0.13 & 0.21 \\
\hline sleeve & 0.30 & - & 0.30 & - & 0.30 & - & 0.30 & - & 0.30 & - & 0.30 & - \\
\hline Total & 3.21 & 3.19 & 3.20 & 3.19 & 3.20 & 3.19 & 3.20 & 3.20 & 3.20 & 3.19 & 3.20 & 3.19 \\
\hline
\end{tabular}

Table 9 : Uncertainties (in \%) on the application of the NCS-10 protocol to the NE2571 ionization chamber (a) and to the PTW31010 (b).

\begin{tabular}{cccccccccccccc}
\hline \hline & \multicolumn{2}{c}{ IEC 61267 } & \multicolumn{2}{c}{ IEC 61267 } & \multicolumn{2}{c}{ IEC 61267 } & \multicolumn{3}{c}{ CCRI180 } & \multicolumn{3}{c}{ CCRI250 } & \multicolumn{3}{c}{ ISO4037 } \\
& RQR6 & \multicolumn{2}{c}{ RQR9 } & \multicolumn{2}{c}{ RQR10 } & \multicolumn{2}{c}{ H00 } \\
& $\mathrm{a}$ & $\mathrm{b}$ & $\mathrm{a}$ & $\mathrm{b}$ & $\mathrm{a}$ & $\mathrm{b}$ & $\mathrm{a}$ & $\mathrm{b}$ & $\mathrm{a}$ & $\mathrm{b}$ & $\mathrm{a}$ & $\mathrm{b}$ \\
\hline $\begin{array}{c}\text { Corrected } \\
\text { reading }\end{array}$ & 0.24 & 0.17 & 0.19 & 0.17 & 0.17 & 0.17 & 0.16 & 0.17 & 0.16 & 0.17 & 0.19 & 0.18 \\
$\begin{array}{c}\text { Air kerma } \\
\text { calibration } \\
\text { factor }\end{array}$ & 0.34 & 0.34 & 0.34 & 0.34 & 0.34 & 0.34 & 0.35 & 0.35 & 0.34 & 0.34 & 0.35 & 0.35 \\
$k_{c h}$ & 1.0 & 1.0 & 1.0 & 1.0 & 1.0 & 1.0 & 1.0 & 1.0 & 1.0 & 1.0 & 1.0 & 1.0 \\
{$\left[\left(\frac{\bar{\mu}_{e n}}{\rho}\right)_{w, a i r}\right]_{2 c m}$} & 1.5 & 1.5 & 1.5 & 1.5 & 1.5 & 1.5 & 1.5 & 1.5 & 1.5 & 1.5 & 1.5 & 1.5 \\
stem & 0.12 & 0.24 & 0.15 & 0.23 & 0.10 & 0.19 & 0.13 & 0.24 & 0.10 & 0.24 & 0.13 & 0.21 \\
sleeve & 0.30 & - & 0.30 & - & 0.30 & - & 0.30 & - & 0.30 & - & 0.30 & - \\
Total & $\mathbf{1 . 8 3}$ & $\mathbf{1 . 8 1}$ & $\mathbf{1 . 8 2}$ & $\mathbf{1 . 8 1}$ & $\mathbf{1 . 8 2}$ & $\mathbf{1 . 8 0}$ & $\mathbf{1 . 8 2}$ & $\mathbf{1 . 8 1}$ & $\mathbf{1 . 8 2}$ & $\mathbf{1 . 8 1}$ & $\mathbf{1 . 8 2}$ & $\mathbf{1 . 8 1}$ \\
\hline \hline
\end{tabular}


Table 10 : Uncertainties associated to calibration factors in terms of absorbed dose to water of the NE2571.

\begin{tabular}{cccccc} 
Beam & $\begin{array}{c}\mathrm{u} N_{\text {D,w,TRS-277 }} \\
(\%)\end{array}$ & $\begin{array}{c}\mathrm{u} N_{\mathrm{D}, \mathrm{w}, \mathrm{TG}-61} \\
(\%)\end{array}$ & $\begin{array}{c}\mathrm{u} N_{\mathrm{D}, \mathrm{w}, \mathrm{IPEMB}} \\
(\%)\end{array}$ & $\begin{array}{c}\mathrm{u} N_{\mathrm{D}, \mathrm{w}, \mathrm{NCS}-10} \\
(\%)\end{array}$ & $\begin{array}{c}\mathrm{u} N_{\mathrm{D}, \mathrm{w}, \text { calorimetry }} \\
(\%)\end{array}$ \\
\hline IEC 61267 RQR6 & 3.51 & 2.20 & 3.22 & 1.84 & 0.72 \\
IEC 61267 RQR9 & 3.51 & 2.19 & 3.21 & 1.83 & 0.71 \\
IEC 61267 RQR10 & 3.50 & 2.19 & 3.20 & 1.82 & 0.64 \\
CCRI 180 & 3.50 & 2.19 & 3.21 & 1.83 & 0.56 \\
CCRI 250 & 3.50 & 2.19 & 3.20 & 1.82 & 0.49 \\
ISO 4037 H300 & 3.51 & 2.19 & 3.21 & 1.83 & 0.55 \\
\hline \hline
\end{tabular}

Table 11 : Uncertainties associated to calibration factors in terms of absorbed dose to water of the PTW31010.

\begin{tabular}{cccccc}
\hline Beam & $\begin{array}{c}\mathrm{u} N_{\text {D,w,TRS-277 }} \\
(\%)\end{array}$ & $\begin{array}{c}\mathrm{u} N_{\text {D,w,TG-61 }}(\%) \\
\left(\% N_{\text {D,w,IPEMB }}\right. \\
(\%)\end{array}$ & $\begin{array}{c}\mathrm{u} N_{\text {D,w,NCS-10 }} \\
(\%)\end{array}$ & $\begin{array}{c}\mathrm{u} N_{\text {D,w,calorimetry }} \\
(\%)\end{array}$ \\
\hline IEC 61267 RQR6 & 3.51 & 2.18 & 3.20 & 1.81 & 0.74 \\
IEC 61267 RQR9 & 3.51 & 2.18 & 3.20 & 1.81 & 0.73 \\
IEC 61267 RQR10 & 3.51 & 2.17 & 3.20 & 1.81 & 0.66 \\
CCRI 180 & 3.51 & 2.18 & 3.20 & 1.82 & 0.58 \\
CCRI 250 & 3.51 & 2.18 & 3.20 & 1.81 & 0.52 \\
ISO 4037 H300 & 3.51 & 2.18 & 3.20 & 1.81 & 0.58 \\
\hline \hline
\end{tabular}

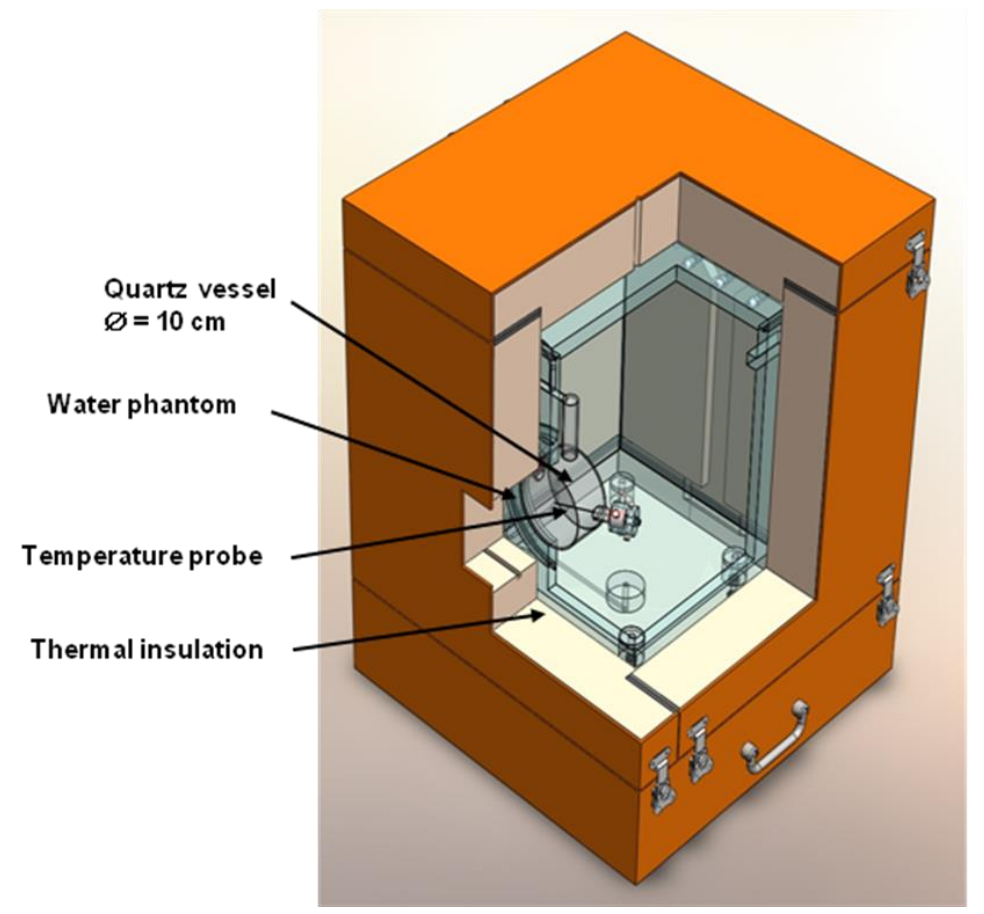

Figure 1 : Schematic drawing of the new LNE-LNHB water calorimeter designed for measurements at $2 \mathrm{~cm}$ depth (the reference depth of medium energy $\mathrm{X}$-rays recommended by dosimetric protocols for radiotherapy) 


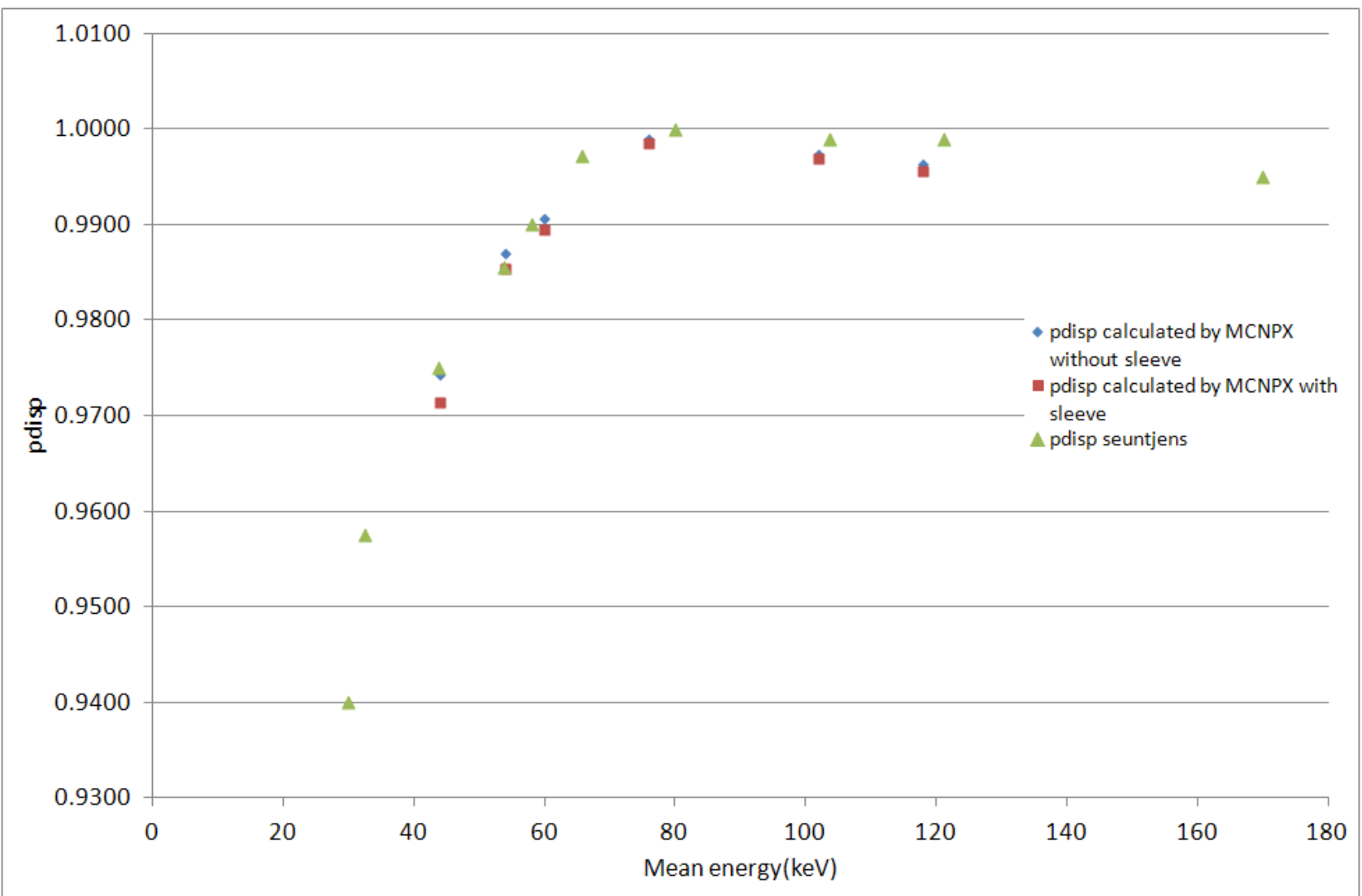

Figure 2 : Comparison of the displacement factors calculated by Monte-Carlo with and without proofing sleeve with Seuntjens data.

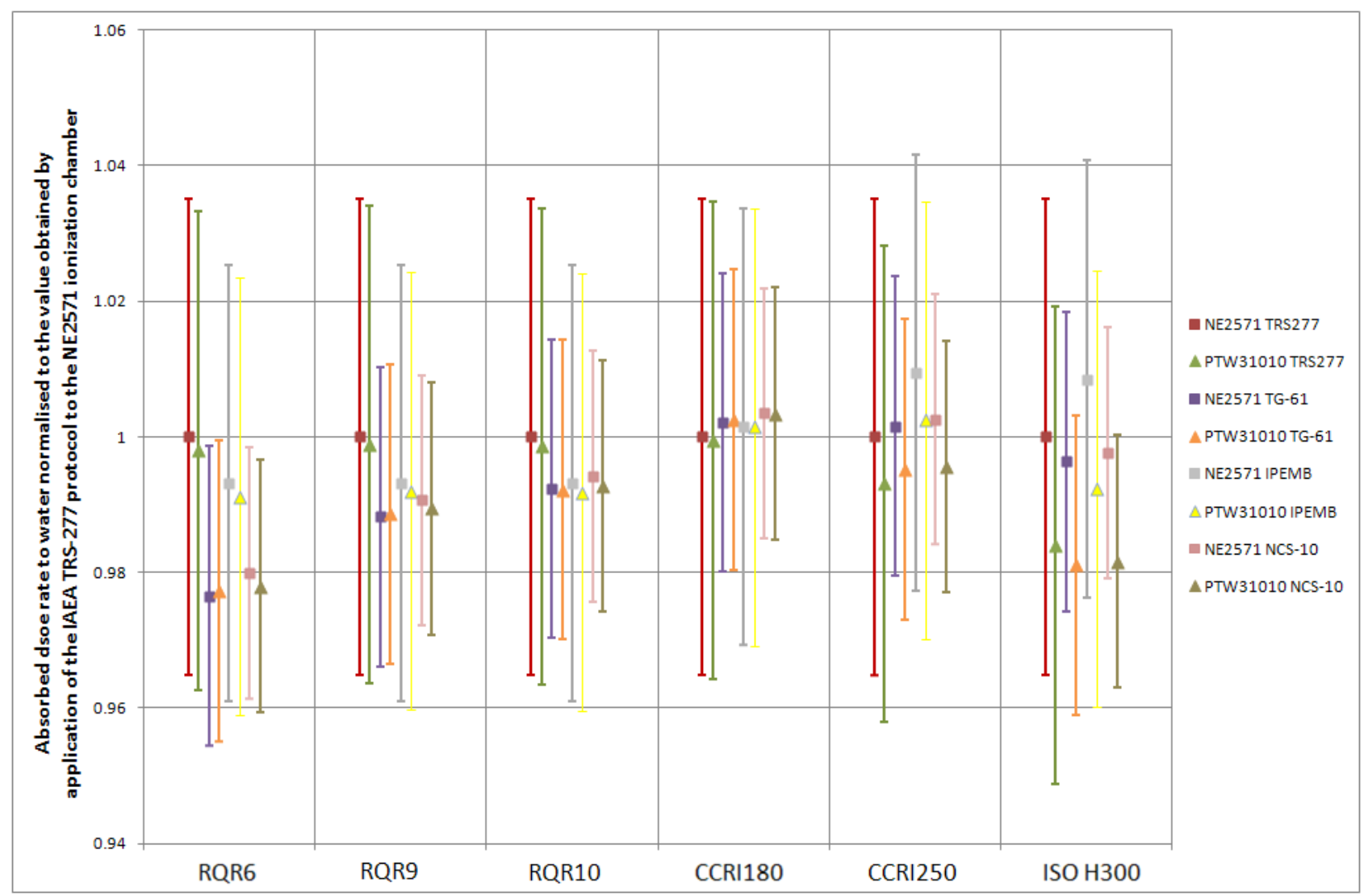

Figure 3 : Comparison in terms of absorbed dose rate to water determined by application of the four protocols studied to the two ionization chambers NE2571 and PTW31010 for the six beams. For each beam, results are normalized to the values obtained by application of the IAEA TRS-277 to the NE2571 ionization chamber. 


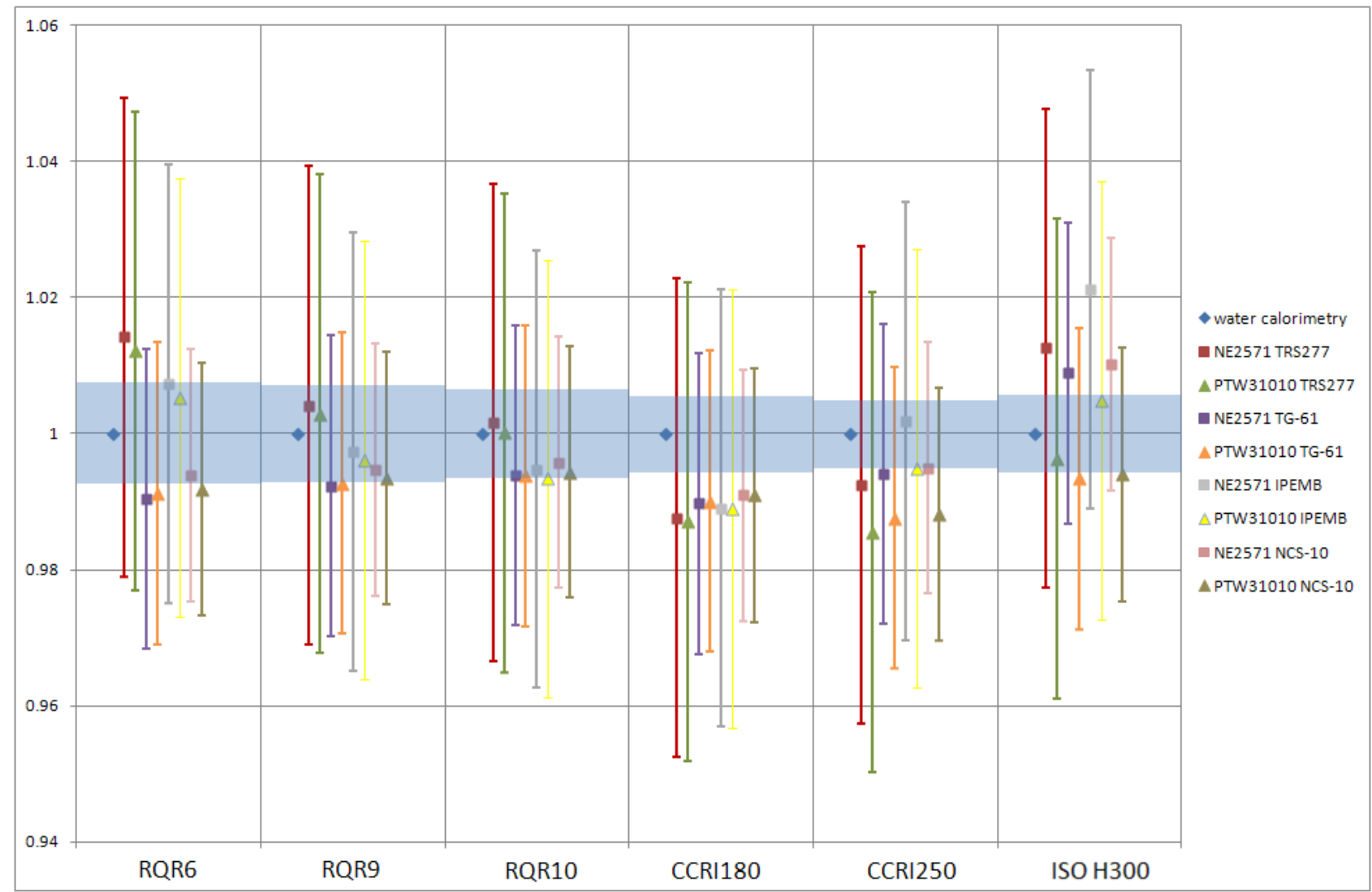

Figure 4 : Comparison in terms of absorbed dose rate to water of the four protocols studied apply to the two ionization chambers NE2571 and PTW31010 for the six beams of interest ; with the calorimetry references. For each beam, values are normalized to the ones obtained by water calorimetry.

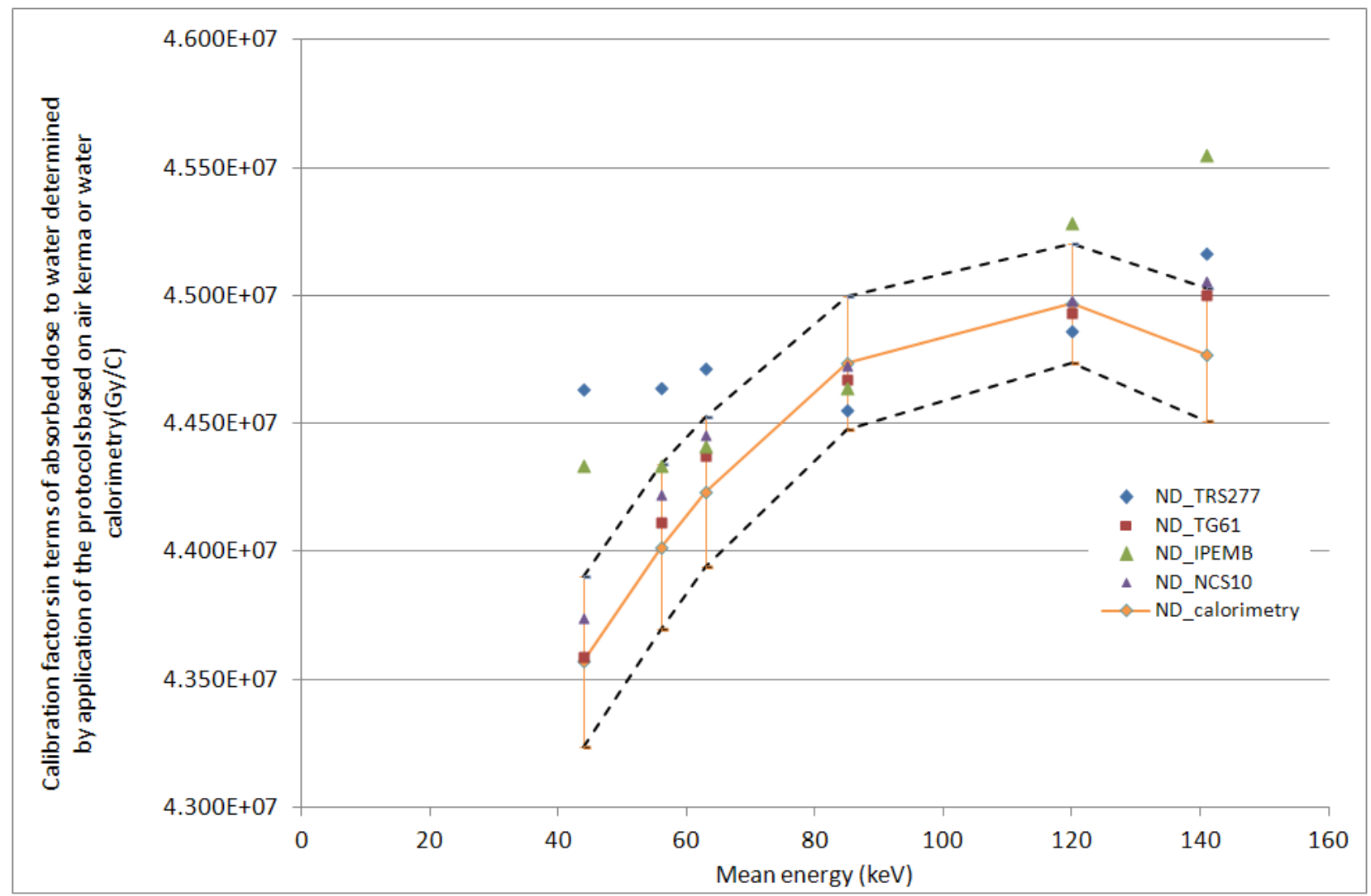

Figure 5: Comparison of calibration factors in terms of absorbed dose to water for the NE2571 ionization chamber. Dashed lines represent the uncertainties associated to the calibration factor determined thanks to calorimetric measurements. 


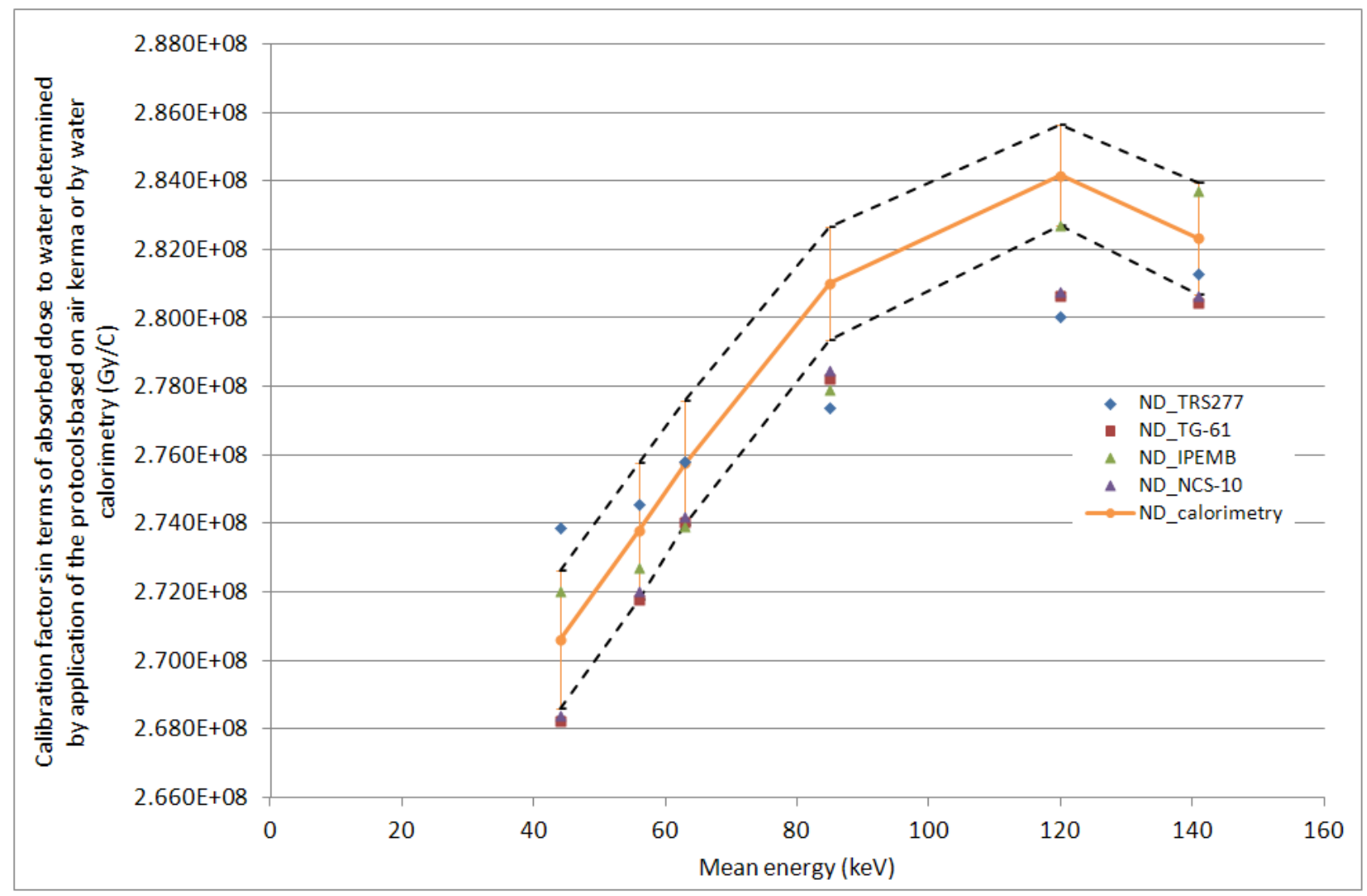

Figure 6 : Comparison of calibration factors in terms of absorbed dose to water for the PTW31010 ionization chamber. Dashed lines represent uncertainties associated to the calibration factor determined thanks to calorimetric measurements. 